\title{
Immediate and long-term results of mitral valve replacement with University of Cape Town mitral valve prosthesis
}

\author{
Velva Schrire and Christiaan N. Barnard \\ From the Cardiac Clinic, Departments of Medicine and Surgery, University of Cape Town; and \\ the Council for Scientific and Industrial Research Cardiovascular-Pulmonary Research Group, \\ in the Department of Medicine, University of Cape Town, South Africa
}

We describe seven years' experience with the University of Cape Town lenticular mitral valve prosthesis in 122 patients.

All the patients had severe mitral valve disease. In 98 severe mitral stenosis was present with or without incompetence and in 24 the dominant or sole lesion was mitral incompetence. Other valves, particularly the tricuspid, were also frequently affected. The disability was severe or total in almost every patient.

One hundred and five patients were discharged from hospital, and in 90 per cent of these the clinical improvement was most gratifying, with the disappearance of pulmonary oedema, paroxysmal dyspnoea, angina pectoris, and congestive cardiac failure. Return to full normal activity including physical work was the rule.

The hospital mortality was 14 per cent and a further 38 per cent died during the follow-up period.

The major post-operative complication was systemic embolism which could occur at any time after operation. The most important factor influencing the frequency of this complication was the nature of the valve seat. A bare steel seat was associated with a 100 per cent embolism, and a significant reduction occurred when a cloth-covered seat of Dacron-velour was introduced. Anticoagulant therapy appeared to prevent large or fresh clots but had no effect on the deposition of fibrin or platelet thrombi. The only other factor of importance was the age of the patient: after the age of 50 life expectancy and trouble-free long-term survival was reduced.

It is nearly seven years since the University of Cape Town mitral valve prosthesis was first introduced. The basic design has already been described (Barnard et al., 1962, 1963). The prosthesis has been shown to function adequately from the haemodynamic point of view (Beck et al., 1965), in that it is completely competent, and a good cardiac output can be maintained at the expense of a tolerable gradient across the prosthesis. In this respect the prosthesis compares favourably with other prosthetic designs in current use (Morrow et al., 1964).

The major problem has been one of postoperative systemic embolism. A series of changes in the design and composition of the valve was introduced in an attempt to eliminate this complication, and these changes in turn introduced new complications.

\section{Subjects and methods}

During the period under review mitral valve replacement was performed in 122 patients. Received is August 1969.
Table I shows the breakdown of these figures into sex and age distribution. There were 50 male and 72 female patients. The ages ranged

TABLE I Age and sex of patients

\begin{tabular}{cccc}
\hline Age $(y r)$. & Male & Female & Total \\
\hline $9-19$ & I & 10 & 11 \\
$20-39$ & 20 & 28 & 48 \\
$40-59$ & 26 & 34 & 60 \\
$60-63$ & 3 & 0 & 3 \\
\hline & 50 & 72 & 122 \\
\hline
\end{tabular}

from 9 to 63, with a peak between 40 and 59. Patients in whom both aortic and mitral valves or mitral and tricuspid valves were replaced have been excluded from this analysis. Tricuspid annuloplasty was also performed in a significant number of patients but these have been included.

Since the procedure was known to be experimental, it was reserved for severely disabled, often terminal, patients. Thus, 84 patients at the 
time of operation had grade 4 disability (New York Heart Association classification) and 36 had grade 3 disability. Many of the former were preterminal, with advanced cachexia and renal and hepatic failure. Nine patients had had bacterial endocarditis, 12 had had previous systemic emboli, and 49 had already had mitral valve surgery on at least one occasion. One patient required renal dialysis before operation. Severely disorganized mitral valves were present in 98 subjects, rigid calcified valves being the rule, producing severe stenosis or dominant stenosis with incompetence. Twenty-four patients had pure mitral incompetence; in 17 of these, palliative procedures such as mitral annuloplasty could not be performed, and in 4 they had failed. Preoperative catheterization and angiocardiographic data were obtained in 73 subjects.

Changes in valve design Four types of valve were used between 1962 and 1968.

Type I valve (May r962-Fune 1965)

The first valve (Barnard et al., 1962) consisted of a fixed unit fashioned from steel coated with Teflon (Fig. ra) and covered with a compressed polyvinyl sponge (Ivalon) and a mobile poppet, lens-shaped, with a flexible stem and a cross bar made from 'Silastic' X-30146.

Type 2 valve (May 1964-May 1965)

This valve was modified by allowing a more discshaped poppet to close on a stainless steel seat (Fig. Ib) without coating or Ivalon.

Type 3 valve ( $F u l y$ 1965-November 1966)

The fixed unit was again covered with Teflon but the mobile portion was made more discshaped with a shorter stem (Fig. Ic).

Type 4 valve (December 1966-October 1968)

The fixed unit was now covered with woven Dacron-velour (Fig. Id), the mobile portion remained disc-shaped with a short stem, and the prosthesis was inserted subannularly.

\section{Model X}

This was used in only one patient who died of massive systemic embolism 3 months after operation.

Anticoagulant policy Most patients were started on anticoagulant therapy in the immediate post-operative period, apart from a short period in 1964 when these drugs were not used.

Follow-up All local patients $(60 \%)$ were seen by one of us (V.S.) at monthly intervals in the Cardiac Clinic Outpatients' Department. $\mathrm{Pa}$ tients living at a distance were seen at least annually. Follow-up information was obtained by letters written to patients and their doctors with whom a close liaison was kept two or three times a year or by direct visits to outlying centres. Particular attention was paid to any history suggesting embolism. The follow-up period in all surviving patients is shown in Fig. 2-5. Cardiac catheterization with angiocardiography was performed in 29 patients usually a year after operation and in 4 again at least two years later.

\section{Results}

Beneficial results of operation One hundred and five patients were discharged from hospital, and in these the clinical improvement from the cardiovascular standpoint was most gratifying. A good functional improvement by clinical criteria was obtained in over 90 per cent of the patients leaving hospital, disability dropping from grade 3-4 to grade o-I. Since all patients were extremely ill at the time of operation, the change produced by this procedure was generally dramatic, with the disappearance of pulmonary oedema, paroxysmal dyspnoea, angina pectoris, and congestive cardiac failure. Return to full normal activity including physical work was the rule, and with the exception of those patients mentioned

FIG. I The four types of mitral valve prosthesis. a. The first valve with an Ivaloncovered steel ring and lens-shaped mobileportion. b. A bare steel seat is present; the poppet is more disc-shaped. c. The mobile portion is now more lens-shaped. $\mathrm{d}$. The seat is covered with cloth Dacron-velour, the poppet is disc-shaped.

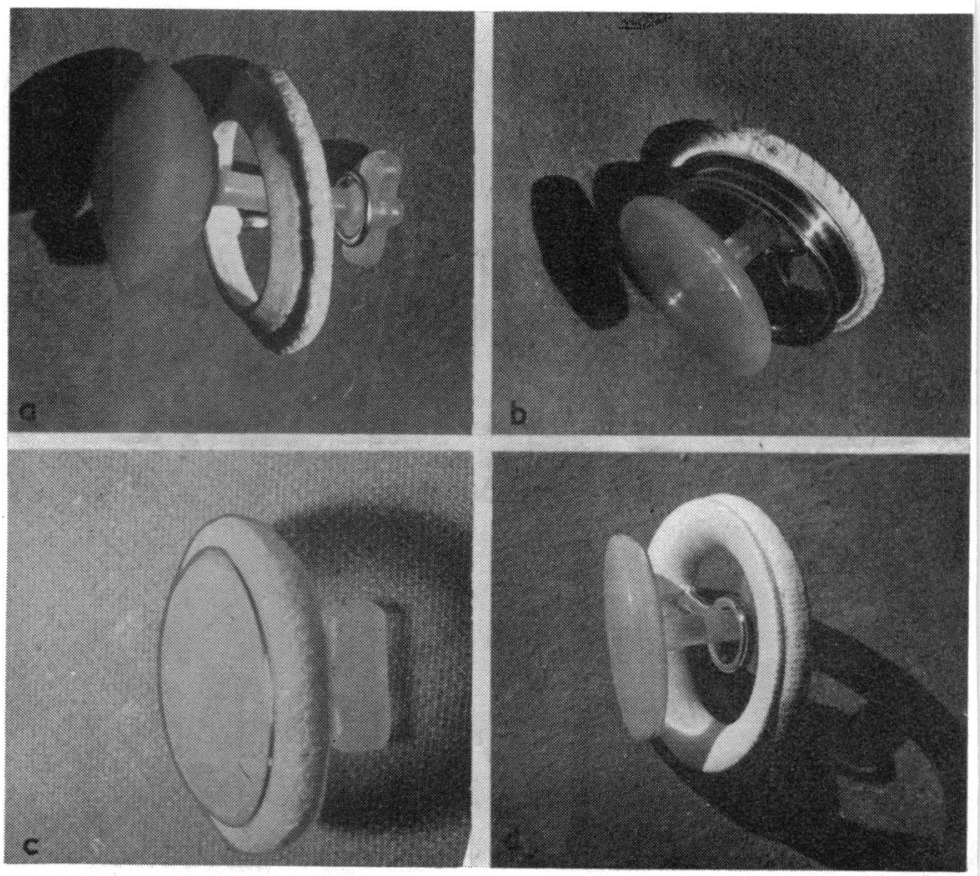


below this improvement has been maintained. Systemic cerebral embolic complications have been solely responsible for residual disability, and have often caused death. Despite the frequency of these episodes the operation has been worth while in most of the patients.

Hospital mortality Seventeen patients (14\%) succumbed (Table 2 and Fig. 2-5), 5

TABLE 2 Hospital mortality

\begin{tabular}{|c|c|c|c|c|c|}
\hline \multirow{2}{*}{$\begin{array}{l}\text { Type } \\
\text { of } \\
\text { valve }\end{array}$} & \multirow{2}{*}{$\begin{array}{l}\text { Patients } \\
\text { operated } \\
\text { on }\end{array}$} & \multicolumn{4}{|c|}{ Cause of death } \\
\hline & & Embolism & $\begin{array}{l}\text { Bacterial } \\
\text { endocarditis }\end{array}$ & Other & Total \\
\hline I & 25 & I & I & 2 & 4 \\
\hline 2 & 23 & 0 & 0 & $\mathbf{I}$ & I \\
\hline 3 & 16 & 0 & 0 & 2 & 2 \\
\hline 4 & 57 & 2 & 2 & 6 & IO \\
\hline $\mathbf{X}$ & I & & & & \\
\hline Total & 122 & 3 & 3 & II & 17 \\
\hline
\end{tabular}

of these dying in the immediate post-operative period. The remaining 12 died within a few days or more after operation; three from uncontrollable arrhythmias, three from massive embolism, three from bacterial endocarditis, two from respiratory complications, and one from cerebral haemorrhage associated with anticoagulant therapy. Two of the patients dying from embolism had massive left atrial thrombosis at necropsy, and one had clots associated with the valve prosthesis. In one of the patients dying of endocarditis, the valve was replaced three times without success, and in another (with fungal endocarditis) twice.

Long-term mortality Forty-six (38\%) of the I05 patients who left hospital alive died during the follow-up period (Table 3 and

\section{TABLE 3 Long-term mortality}

\begin{tabular}{|c|c|c|c|c|c|}
\hline \multirow{2}{*}{$\begin{array}{l}\text { Type } \\
\text { of } \\
\text { valve }\end{array}$} & \multirow{2}{*}{$\begin{array}{l}\text { Patients } \\
\text { dis- } \\
\text { charged } \\
\text { from } \\
\text { hospital }\end{array}$} & \multicolumn{4}{|c|}{ Cause of death } \\
\hline & & $\begin{array}{l}\text { Endo- } \\
\text { carditis }\end{array}$ & Embolism & $\begin{array}{l}\text { Heart } \\
\text { failure }\end{array}$ & Other \\
\hline $\mathbf{I}$ & 21 & I & 7 & 3 & 0 \\
\hline 2 & 22 & 3 & Io & o & $\mathbf{I}$ \\
\hline 3 & 14 & I & 5 & 0 & 2 \\
\hline$\stackrel{4}{x}$ & $\begin{array}{r}47 \\
1\end{array}$ & $\mathbf{I}$ & 7 & 3 & 2 \\
\hline Total & 105 & 6 & 29 & 6 & 5 \\
\hline
\end{tabular}

Where death was due to a combination of factors the case is listed under the main cause.
Fig. 2-5). Twenty-nine of these deaths were due directly or indirectly to cerebral embolisms. This whole problem is considered in

FIG. 2 Results of replacement by Type I prosthesis. In these and subsequent figures, black bars represent episodes of clinical embolism. The width of the bar represents the severity of the neurological consequences the broader the bar the worse the cerebral deficit. The cross-hatched areas indicate prolonged incapacitating, of ten permanent, organic neurological syndromes, usually paralysis. $L T A=$ long-term anticoagulant therapy; $\dagger=$ death; $C C F=$ congestive heart failure; $A B E, S B E=$ acute or subacute bacterial endocarditis; $C I=$ cardiac infarction and $M I=$ mitral incompetence. $G I=$ gastrointestinal.

In the first five patients, the valve was inserted at the valve ring; in the following $I 7$ patients, the valve was inserted above the ring, and in the last three below the ring.

There were 6I episodes of embolism in 943 patient months (I per 15 months). Only 2 patients had no embolism at any time. It can be seen that the patients were never free from the risk of embolism. Even as long as five years after operation this complication might occur without warning.

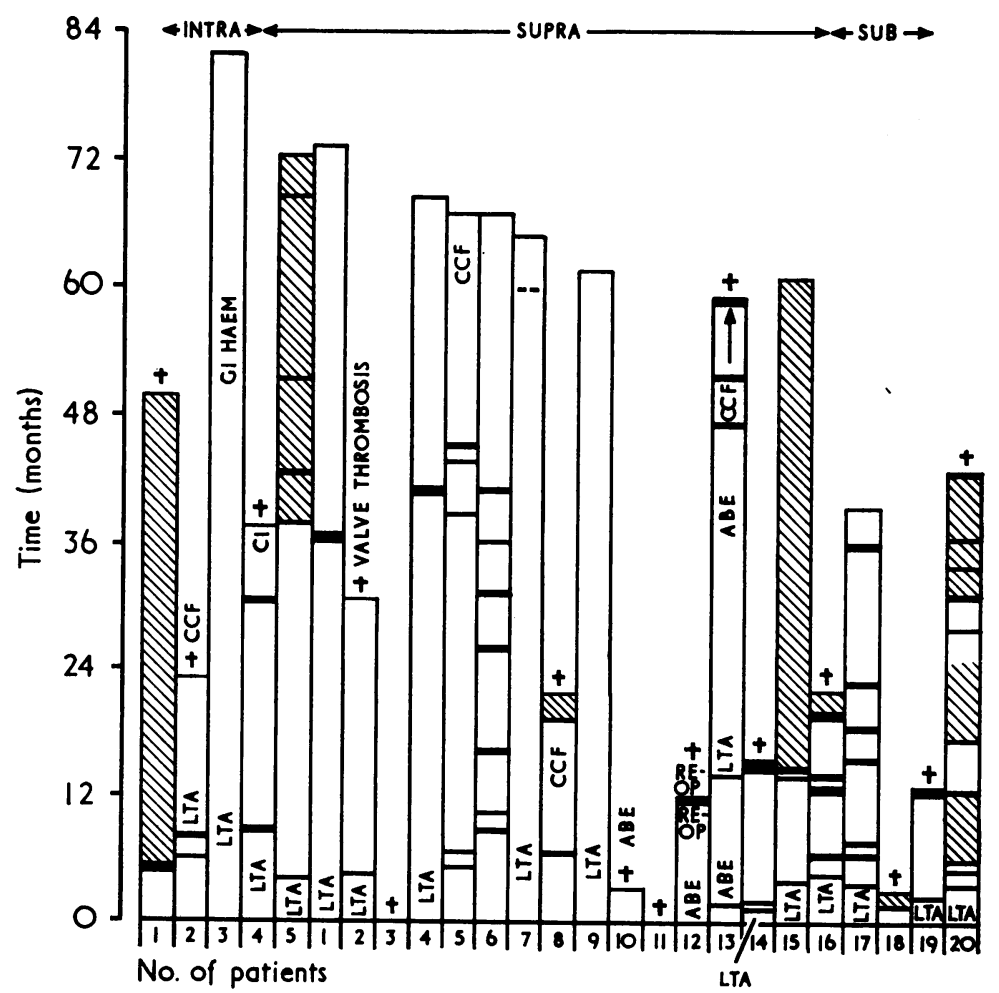


detail in the section on long-term complications. Five patients died from bacterial endocarditis; in most of these the infection was implanted at the time of operation and staphylococci, coagulase positive or negative, were the usual offending organisms. Bacterial endocarditis on the prosthetic valve is not invariably fatal and four patients were cured by vigorous antibiotic therapy. A sixth patient died of fulminating staphylococcal septicaemia, and at necropsy the valve was found to be spared.

Six patients died of congestive cardiac failure. (A seventh developed resistant heart failure four years after operation but has not yet died.) One patient had chronic airways obstruction and was only temporarily improved by operation. One developed severe systemic hypertension secondary to renal embolism and died in heart failure with intractable arrhythmia. Cardiac catheterization showed a normally functioning mitral valve without incompetence and only moderate stenosis. One patient who recovered from two attacks of bacterial endocarditis, for each of which he had received six months antibiotic treatment, developed heart failure four years after operation, and necropsy confirmed the presence of gross cardiomegaly.

Five of these six patients died from 3 to 19 months after operation, with an average lifespan of 14 months after operation. Severe myocardial dysfunction was confirmed by catheterization studies in all and coronary artery disease was found in only one of the four who came to necropsy. The reason for the myocardial disease was not clear and there are many possible contributory factors, such as coronary artery atherosclerosis or embolism, the effects of perfusion, the effects of other valve lesions, rheumatic myocarditis, hypertension, infections, and cardiomyopathy.

There were five miscellaneous deaths. One patient developed ventricular fibrillation following cardioversion for atrial fibrillation. One died of haemorrhage and other complications after a cholecystectomy for gall-stones. One died suddenly and unexpectedly a year after operation having made a complete functional recovery. The remaining two were thought to have died of 'pneumonia'. There was no necropsy information available on the latter three patients so that the cause of death was never established.

\section{Long-term complications \\ Residual mitral incompetence}

Three patients had residual mitral systolic murmurs after operation, and mitral in-

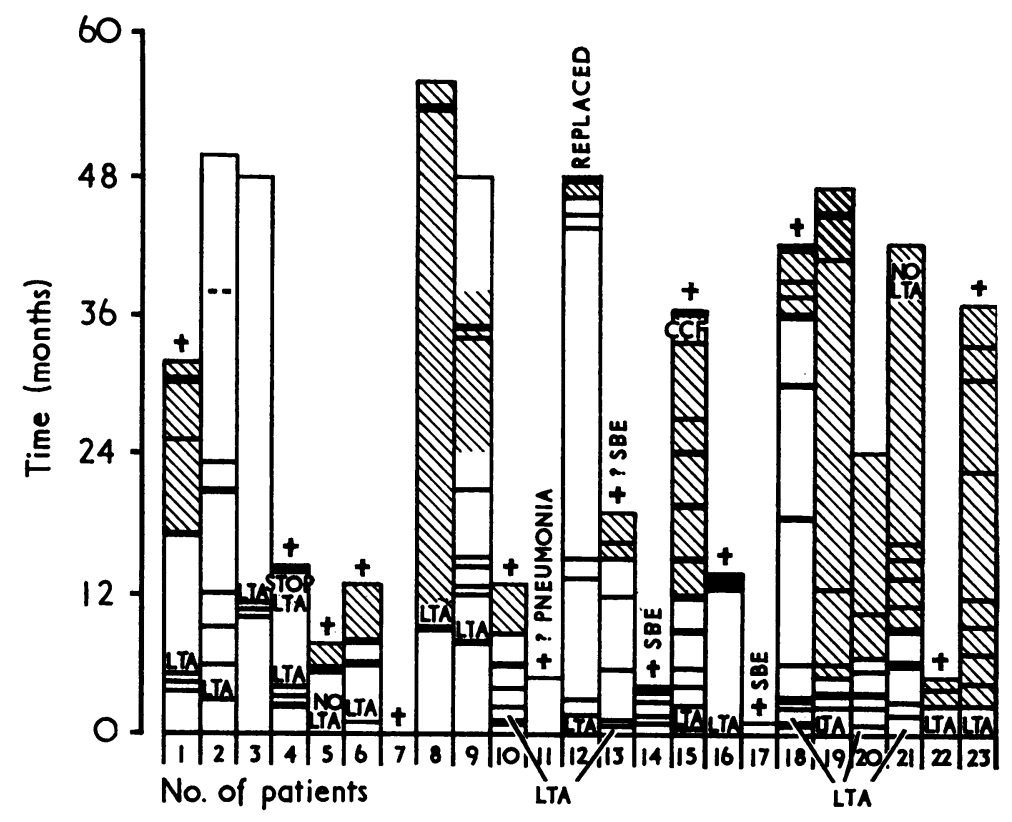

FIG. 3 Results of replacement by Type 2 prosthesis. With the introduction of a steel ring, embolism became immediately more frequent and more disabling. No patient escaped this complication and only two have received long-lasting benefit. There were 109 embolic episodes in 607 patient months (I per 5.6 months). Symbols as for Fig. 2.

FIG. 4 Results of replacement by Type 3 prosthesis. This prosthesis was placed subannularly. There were 28 embolic episodes in 317 patient months (I per II months). Symbols as for Fig. 2.

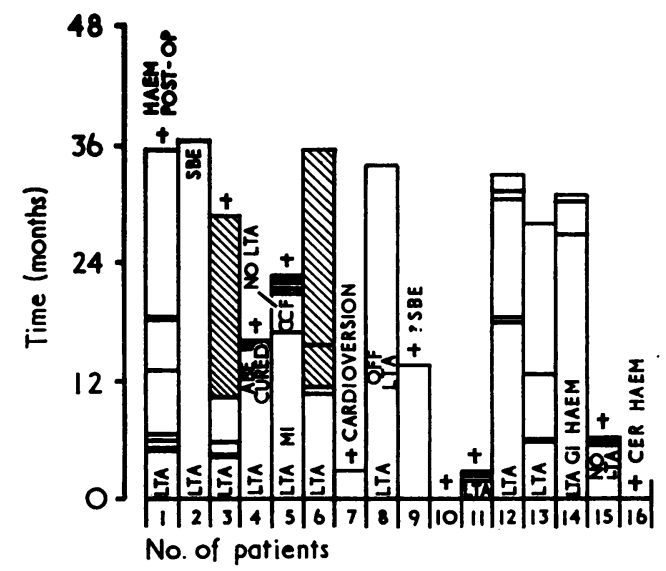


competence was confirmed at cardiac catheterization in two of these. In one the valve was not replaced because of severe impairment of left ventricular function. In the other valve replacement was followed by dramatic clinical improvement until he died from a fulminating staphylococcal septicaemia.

\section{Mitral valve obstruction}

One patient developed severe mitral valve obstruction due to thrombosis around the valve. She refused further operation and died in pulmonary oedema. Another patient, who was much improved by operation and lost all her symptoms, showed the murmurs of mitral stenosis (Fig. 6). Cardiac catheterization confirmed the presence of mitral stenosis, with a mean gradient of $9 \mathrm{~mm}$. $\mathrm{Hg}$ and a calculated mitral valve area of $1.4 \mathrm{~cm}^{2}$. This case was unique in our experience and the situation was never adequately explained.

\section{Valve wear}

Three patients developed mitral incompetence. The first occurred 28 months after operation and was recognized by the appearance of an apical systolic murmur and the return of pulmonary congestion, and at necropsy 9 months later imbibition of fat had produced an irregularity of the lens poppet interfering with proper sealing during left ventricular systole (Fig. 7). After the introduction of cloth-covered valves (Type 4) two were so worn that replacement became necessary (Fig. 8). The clinical diagnosis was based on the appearance of mitral systolic murmurs and the recurrence of symptoms, and confirmed by cardiac catheterization. The curing of the Silastic of the mobile portion was done elsewhere in these two patients. Evidence was obtained at necropsy in other patients, that more wear on the mobile portion developed when clothcovered seats were used than with Ivalon, so that changing from a relatively large lens to a small flat disk might prove disadvantageous.

\section{Haemolytic anaemia}

This has not been an important problem with the mitral valve, unlike our experience with the cloth-covered aortic valve (Schrire et al., 1970). One patient developed haemolytic anaemia when mitral incompetence appeared. One other patient with aortic and mitral valve replacements developed intractable haemolytic anaemia which was only cured when the incompetent mitral valve was replaced.

\section{Systemic embolism}

By far the most frequent and serious complication was the development of systemic embolism. Indeed only 34 of the ro5 patients who left hospital escaped it (Table 4 and

TABLE 4 Long-term incidence of embolism

\begin{tabular}{llll}
\hline $\begin{array}{l}\text { Type } \\
\text { of } \\
\text { valve }\end{array}$ & $\begin{array}{l}\text { Patients } \\
\text { discharged } \\
\text { from } \\
\text { hospital }\end{array}$ & $\begin{array}{l}\text { Patients } \\
\text { developing } \\
\text { embolism }\end{array}$ & $\begin{array}{l}\text { Rate of } \\
\text { embolism in } \\
\text { patient months }\end{array}$ \\
\hline I & 21 & I9 & I in I5 \\
2 & 22 & 22 & I in 6 \\
3 & I4 & I0 & I in I I \\
4 & 47 & I9 & \\
X & I & I & I in I I \\
\hline Total & IO5 & 71 & \\
\hline
\end{tabular}

Fig. 2-5). Cerebral embolism was the main danger and accounted for most of the longterm morbidity as well as the mortality.

Embolism was usually recurrent, but many patients initially had only minor episodes with transient disability which did not seriously interfere with daily activities. Of the patients who had emboli, temporary improvement was obtained in 18 and lasting benefit in 28 and since the improvement in cardiac function was so conspicuous, the

FIG. 5 Results of replacement by Type 4 prosthesis. With this prosthesis, placed subannularly, embolic episodes were less frequent; 30 in 690 patient months ( $I$ per 24 months). $H F=$ heart failure.

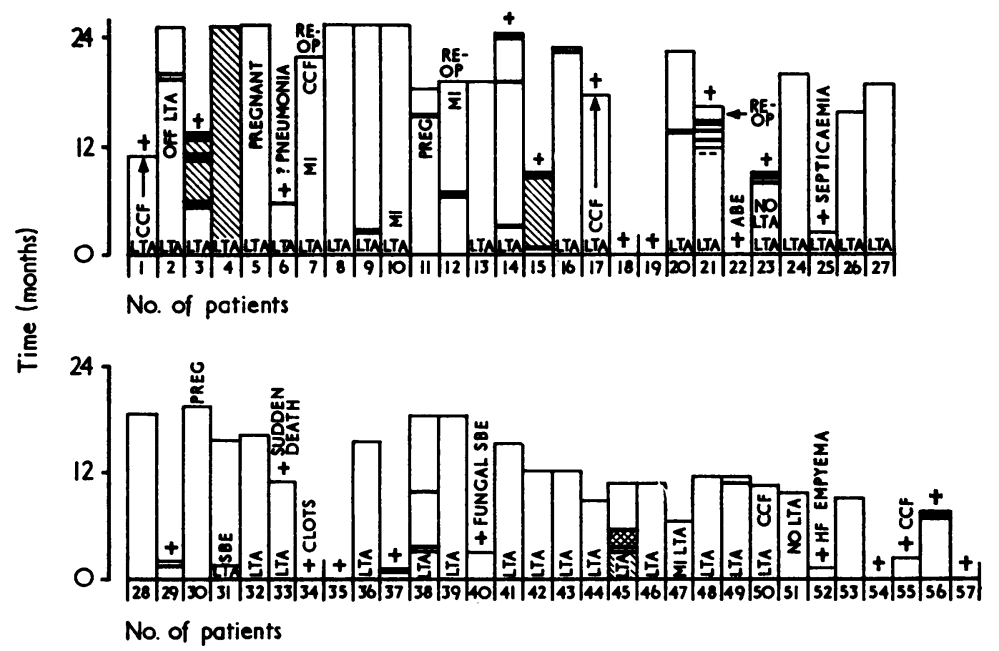


surgical reward in these fortunate patients was considerable.

In some patients small cerebral episodes led to minor alterations in personality or in some faculty. For example, a business executive whose hobby was music complained of an inability to appreciate Beethoven to the extent that he had before his first cerebral embolism. Unfortunately he continued having repeated episodes during one of which he developed a homonymous hemianopia. Considerable intellectual deterioration developed three and a half years after operation. This progressed, and in an attempt to halt the process the prosthetic valve was replaced by a xenograft after four years. At operation small fibrin deposits were present on the rim of the valve. There was an immediate and dramatic cerebral improvement with remarkable restoration of intellectual functions. Unfortunately, the xenograft had later to be replaced by a Starr valve, following which a cerebral episode recurred.

A number of patients (cross-hatched in Fig. 2-5) became neurological cripples. In some the initial episode was a major hemiplegia from which they made a considerable recovery before a further massive and often fatal embolus. Though all had evidence of motor or sensory involvement, none were bed-ridden or chair-ridden from an inability to walk. The major disability in a few subjects was one of organic dementia ranging from loss of memory and inability to concentrate, to hallucinations, paranoia, change in the standard of social behaviour, and excessive sexual desire. This syndrome of pre-senile dementia was the most distressing aftermath encountered. In some patients however, gradual improvement has occurred, the final neurological adjustments being less gloomy than anticipated.

In some patients, particularly the older subjects, exactly the same transitory neurological disturbance occurred repeatedly, without any noticeable deterioration in physical signs between attacks. These attacks could often be correlated with situations in which the cardiac output was temporarily reduced due to postural hypotension, and could to a certain extent be avoided by the patient adopting measures which prevented a sudden drop in cardiac output. A situation thus developed exactly analogous to the syndrome of extracerebral arterial obstruction in which transitory neurological disturbances occur. The mechanisms are probably similar, either a maldistribution of blood as a result of changes in cardiac output, or repeated small platelet emboli arising from the valve, being swept along a stereotyped pathway and being deposited repeatedly in the same area.

FIG. 6 Phonocardiogram of a patient showing the murmurs of mitral stenosis following valve replacement. The top phonocardiogram shows the findings normally encountered in patients with a University of Cape Town mitral prosthesis. The first sound is accentuated, the 'opening snap' is late (0.15 sec. after A2) and multiple, presumably due to oscillation of the poppet, and there are no murmurs. The lower tracing comes from a unique case with classical murmurs of mitral stenosis. There is a mid-diastolic murmur following the opening snap with pre-systolic accentuation of the diastolic murmur ending with the accentuated delayed first heart sound (mitral valve closure).

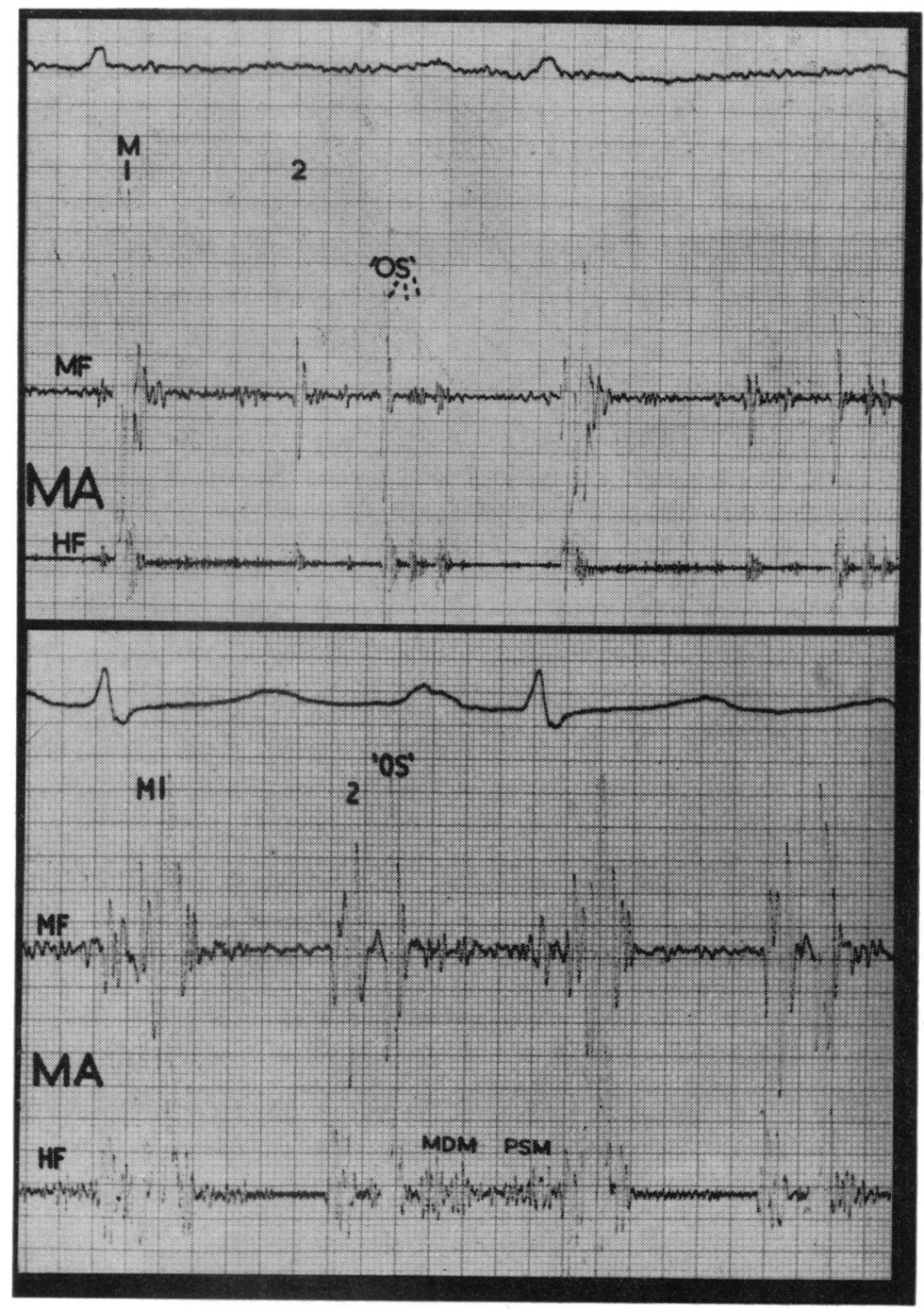


The pathological findings in the brains were those of small cerebral softenings where the episodes were minor, with infarction or haemorrhage in larger areas when embolism was the immediate cause of death. The source of embolism was generally the prosthetic valve. Small platelet fibrinous thrombi formed at the junction between the valve ring and the wall of the atrium; less frequently on the ventricular surface (Fig. 9). Large fleshy clots formed from all the blood elements were not found in relation to the valve except in one patient who died in pulmonary oedema, in whom the valve was occluded. This patient had discontinued anticoagulants some time before death. This type of clot was also found in patients dying after recent operation; usually in the left atrium, either in the appendage, on the posterior wall, or at the atriotomy site.

\section{Factors associated with embolism}

The following factors were analysed and found to have no bearing on the incidence or extent of embolism: a history of pre-operative embolism, arrhythmia (particularly atrial fibrillation) before or after operation, and the pre-operative haemodynamic findings of pulmonary vascular resistance, pulmonary artery pressure, pulmonary wedge or left atrial pressure, mitral valve gradient, and cardiac index.

The age of the patient at the time of operation appeared to influence the prognosis. Patients under 35 fared better than those over 50. In the latter group (26 patients) only 3 did not have an embolus, and all but five either died or became severely incapacitated.

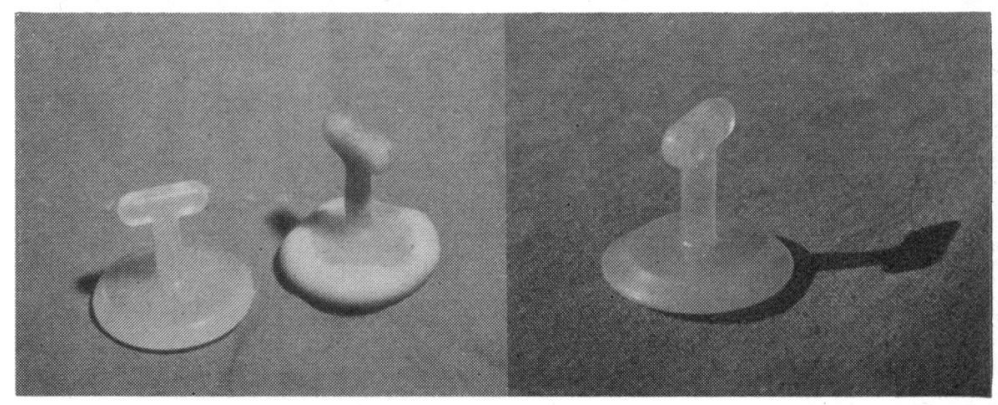

FIG. 7

FIG. 8

FIG. 7 Appearance of valve 28 months after operation. Imbibition of fat has produced an irregular poppet resulting in mitral incompetence (normal poppet on left).

FIG. 8 Ball wear. Ball wear of disc-shaped poppet resulting in mitral incompetence.

With regard to the effect of anticoagulant therapy on the incidence of these emboli, no accurate statistical analysis can be made from our data, as it has been impossible for us to ensure satisfactory prothrombin levels on a long-term basis. Many patients could not attend the hospital's anticoagulant clinic, and were controlled in rural districts where facilities were often unsatisfactory. It was always difficult to know how careful the patient had been in maintaining therapy. Because of these inconsistencies we can merely record our impressions.

Emboli were not more frequent in the patients who did not receive anticoagulants. Nevertheless, two patients in this group who did have emboli were subsequently treated with anticoagulants and have not had a

FIG. 9 Necropsy appearance of thrombus on the prosthetic valve. Photographs of valve ring from (a) atrial and (b) ventricular aspects showing sites of thrombus formation.

(a)

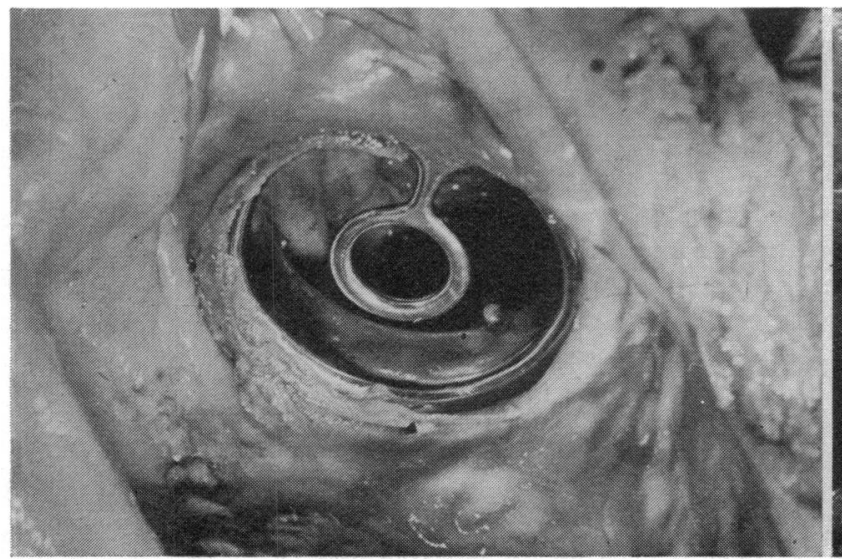

(b)

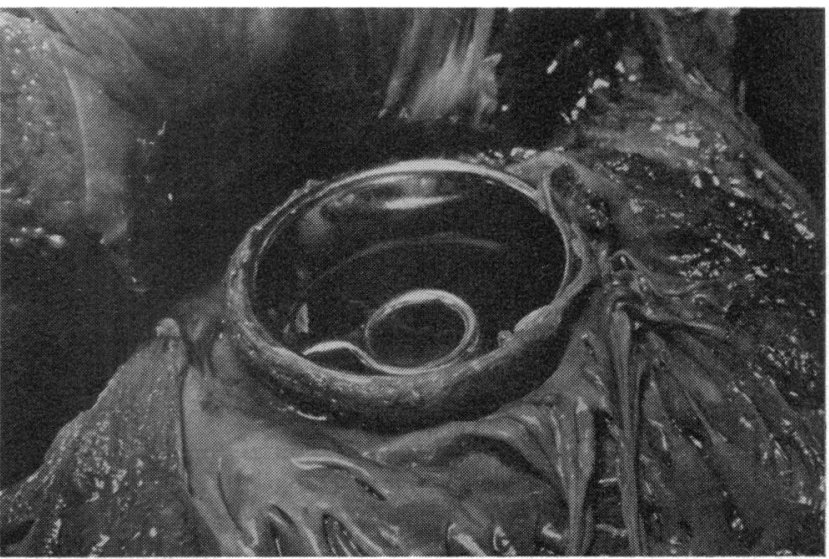


recurrence. There have also been patients who for one reason or another suddenly stopped taking anticoagulants, and this was followed by an embolic episode which was often catastrophic. Others have sustained emboli when their level of control has been inadequate. On the other hand, we have several patients who have had emboli, often multiple, while their prothrombin indices have been satisfactory (40-60\%). As has been indicated earlier, patients dying while on anticoagulants have not shown massive thrombus formation in the region of the prosthesis, whereas the one case that did show gross changes was not on anticoagulants. We feel that anticoagulants do prevent bulky thrombus formation in the left atrium, but have little or no effect on the formation of the small fibrinous thrombi which have such profound cerebral effects. The most important factors responsible for embolism appear to have been the surgical technique and the design of the prosthesis (Tables 3 and 4).

Type I valve (Fig. Ia) May I962-fune 1965. In the first five patients the valve was inserted at the mitral ring, in the following 18 above the ring, and in the last three below the ring. Anticoagulants were used after the first few cases when embolism was encountered. Because of the high incidence of embolism (Fig. 2) the valve was modified.

Type 2 valve (Fig. Ib) May 1964-May 1965. The use of this valve was soon followed by a catastrophic incidence of embolism (Fig. 3) so that it was abandoned.

About this time studies on dogs (Barnard and Barnard, 1966) showed that the longterm survival rate following mitral valve replacement was significantly improved by placing the valve ring on the ventricular surface of the annulus. All animals in which the prosthesis was placed on the atrial surface of the annulus succumbed from massive thrombosis, whereas six animals survived the subannular replacement procedure. The tendency for thrombus formation in dogs is thus greatly reduced by subannular replacement - in which the foreign material of the valve ring is exposed to rapid flow, and the considerable pressure changes that occur in the left ventricle with each cardiac cycle. The University of Cape Town prosthesis has the advantage that it can be readily placed in this position, and because of its small bulk does not cause ventricular damage or obstruction to outflow. After July 1965, therefore, the prosthesis was placed in the subannular position and routine anticoagu- lant therapy was begun on the third postoperative day in all patients.

Type 3 valve (Fig. Ic) fuly I965-November 1966 The use of this valve in the subannular position appeared to make some difference to the incidence of post-operative embolism (Fig. 4) but it was slight and insignificant.

Type 4 valve (Fig. Id) September 1966October 1968 With this prosthesis, inserted subannularly, the incidence of embolism dropped (Fig. 5) and this is particularly noticeable in the last 30 patients.

From the above evidence, we conclude that the most important factor responsible for post-operative embolism is the design of the valve. With the bare steel seat, the incidence of embolism was 100 per cent. This was only slightly lessened by coating the frame with Ivalon, and inserting the valve in the subannular position. The incidence of embolism was only reduced when the valve seat was covered with Dacron-velour. This is evident in Fig. 10, which shows the incidence of embolism in the first 24 months after operation with each of the four valves. It is evident that the number of emboli dropped considerably with the introduction of a cloth-covered valve. Despite this undoubted and gratifying improvement, the incidence of emboli remained distressingly high so that this valve was not used after October 1968.

\section{Discussion}

Replacement of the mitral valve with the University of Cape Town prosthesis was regarded as an experimental procedure. For this reason only desperately ill patients with a limited life expectancy and much restricted lives were offered this operation. Almost half the patients had already had at least one operation on the mitral valve and several had had two or three attempts at surgical correction. Every effort was made to preserve the valve, and replacement was performed only when this was unavoidable. By this time symptoms had been present for an average of ro years and there were usually severe chronic lung congestion and pulmonary vascular changes, and often chronic venous congestion with hepatomegaly and oedema. Other valves were frequently diseased and the tricuspid valve was commonly incompetent.

Despite the late stage of the disease a hospital mortality of 14 per cent was obtained. This figure could undoubtedly be considerably improved were it possible to 


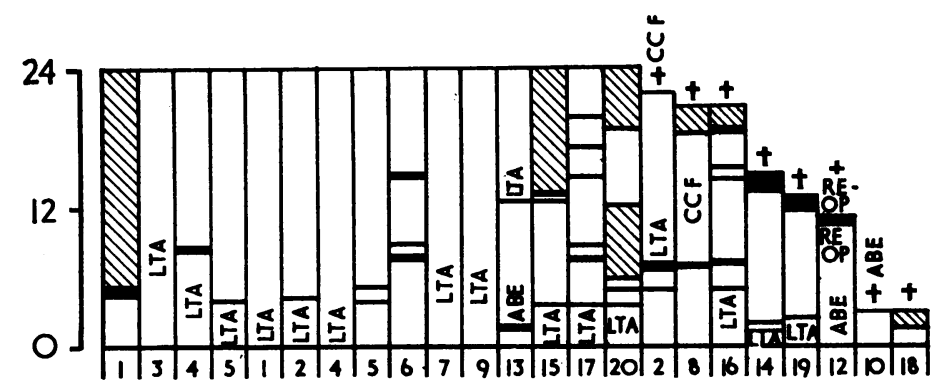

No. of patients
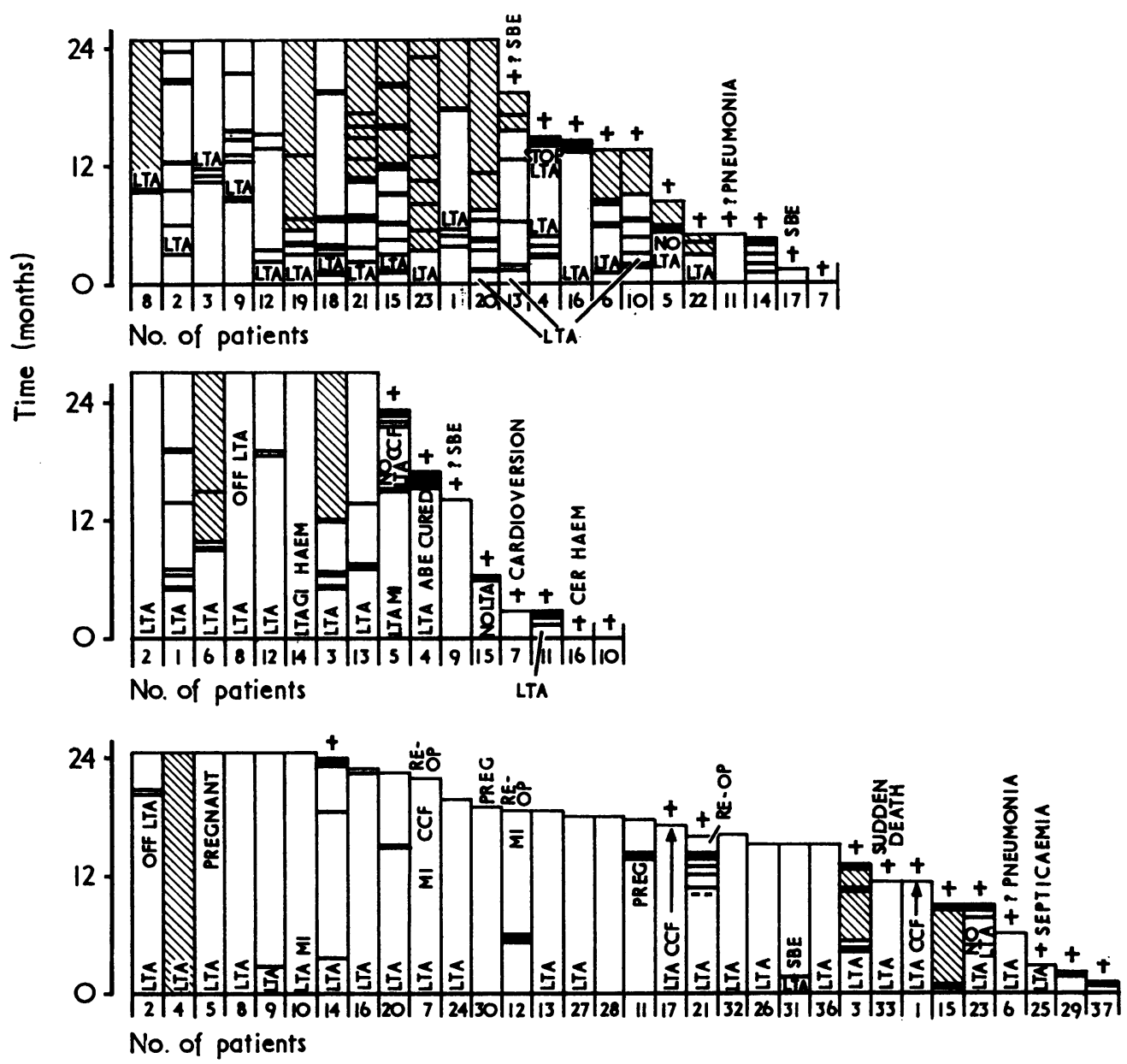

FIG. IO Comparison of the incidence of embolism in the 4 valves. To eliminate the unequal lengths of the follow-up period the first 24 post-operative months only in the four valve types have been charted. The reduced incidence of embolism in the cloth-covered valve is apparent.

advise operation at an earlier stage in the disease. In the surviving patients clinical evidence indicated that cardiovascular function had been much improved. Haemodynamic assessment of cardiac function by catheterization studies (Beck et al., 1965) in the first score or so of patients investigated approximately a year after operation showed a conspicuous improvement. The valves were all competent as judged by cine-angiography. At rest a mean diastolic pressure gradient varying between $\mathrm{I} \cdot 2$ and $12 \mathrm{~mm}$. $\mathrm{Hg}$ was present resembling mild mitral stenosis. Exercise produced a rise in both left atrial 
and pulmonary arterial pressures, as might be expected in patients with mild mitral obstruction. The pulmonary artery pressure fell dramatically in some patients and the estimated resistance generally fell to onefourth of the pre-operative level. In the two patients who failed to show sustained haemodynamic improvement this was due to factors other than the mitral valve. Thereafter post-operative studies were only performed in special circumstances; as, for example, in patients who failed to maintain their initial clinical improvement, or to assess the degree of incompetence when a systolic murmur was present or appeared or where silent mitral incompetence was suspected (Rockoff et al., I966).

A radiological assessment of improvement in cardiac function was made in $\mathbf{3 2}$ patients (Gotsman et al., 1967) one year after operation. Heart volume, cardiothoracic ratio, left atrial enlargement, left and right ventricular enlargement, pulmonary arterial enlargement, and changes in the pulmonary vascular pattern were assessed. Heart volume and cardiothoracic ratio decreased in 19 patients but returned to normal in only 5 of these. The greatest improvement was observed in severe mitral incompetence. Residual lower zone vaso-constriction and regional redistribution of the pulmonary vascular bed as reflected by the persistent distension of the upper lobe pulmonary veins persisted, but improved considerably, as did the pulmonary parenchymal changes.

The major problem has been the occurrence of systemic embolism. In closed mitral valvotomy, anticoagulants have been claimed to reduce the incidence of post-operative embolism (Smith et al., 1965), but in our experience of mitral valve replacement this form of therapy has been unsuccessful. The most important factor influencing the incidence of embolism appears to be the design of the valve. With the bare steel seat the incidence was roo per cent and it was only reduced significantly when the valve seat was covered with Dacron-velour. Other workers have had a similar experience (Bonchek and Braunwald, 1967; Starr, Herr, and Wood, 1967; Beall et al., 1968; Harken et al., 1968). Though the incidence of post-operative embolism has been reduced it is still distressingly high, and there is a pressing need for further work on the development of a complicationfree mitral prosthetic valve.

Ball variance and haemolytic anaemia have been encountered since the introduction of the cloth-covered valve, but the incidence of these complications has been so low that they have presented no real problem.
We wish to thank our colleagues in the Cardiac Clinic, particularly Dr. W. Beck, and in the Cardio-Thoracic Unit, Drs. R. P. Hewitson, M. Barnard, and T. G. O'Donovan, for their untiring efforts in the investigation and treatment of our patients; Dr. J. G. Burger, for permission to publish, and the South African Council for Scientific and Industrial Research and the City Council of Cape Town for their continued financial support.

\section{References}

Barnard, C. N., Goosen, C. C., Holmgren, L. V., and Schrire, V. (I962). Prosthetic replacement of the mitral valve. Lancet, 2, 1087.

, Schrire, V., Goosen, C. C., and Holmgren, L. V. (I963). Complete replacement of the mitral valve. South African Medical fournal, 37, 97.

Barnard, M. S., and Barnard, C. N. (1966). Thromboembolic complications following total mitral valve replacement with the University of Cape Town lenticular mitral prosthesis. South African Medical fournal, 40, 263.

Beall, A. C., Jr., Bloodwell, R. D., Liotta, D., Cooley, D. A., and De Bakey, M. E. (I968). Clinical experience with a Dacron velour-covered Teflondisc mitral-valve prosthesis. Annals of Thoracic Surgery, 5, 402.

Beck, W., Fergusson, D. J. G., Barnard, C. N., and Schrire, V. (1965). Hemodynamic findings following replacement of the mitral valve with the University of Cape Town prosthesis. Circulation, 32, 721.

Bonchek, L. I., and Braunwald, N. S. (1967). Thrombus resistant rigid prosthetic heart valves covered with porous synthetic fabric. Transactions. American Society for Artificial Internal Organs, 13, 101.

Gotsman, M. S., Beck, W., Barnard, C. N., and Schrire, V. (1967). Changes in the appearance of the chest radiograph after a repair or replacement operation on the mitral valve. British fournal of Radiology, 40, 724.

Harken, D. E., Matloff, J. M., Zuckerman, W., and Chaux, A. (1968). A new mitral valve. Fournal of Thoracic and Cardiovascular Surgery, 55, 369.

Morrow, A. G., Clark, W. D., Harrison, D. C., and Braunwald, E. (1964). Prosthetic replacement of the mitral valve. Operative methods and the results of preoperative and postoperative hemodynamic assessments. Circulation, 29, Suppl. I, p. 2.

Rockoff, S. D., Ross, J., Oldham, N. N., Mason, D. T., Morrow, A. G., and Braunwald, E. (I966). Ventriculo-atrial regurgitation following prosthetic replacement of the mitral valve. Angiocardiographic and hemodynamic findings. American fournal of Cardiology, 17, 817.

Schrire, V., Beck, W., Hewitson, R. P., and Barnard, C. N. (1970). The immediate and long-term results of aortic valve replacement with the University of Cape Town aortic valve prosthesis. British Heart Fournal, 32, 255.

Smith, B., Umapathy, A., Bentall, H. H., and Cleland, W. P. (1965). Anticoagulants and mitral valvotomy. British Heart fournal, 27, 618.

Starr, A., Herr, R. H., and Wood, J. A. (1967). Mitral replacement. Review of six years' experience. fournal of Thoracic and Cardiovascular Surgery, 54, 333. 